\title{
Emulsion Liquid Membrane for Cadmium Removal: Experimental Results and Model Prediction
}

\author{
A. L. Ahmada*, Adhi Kusumastutia,b, M. M. H. Shah Buddina, D. C. J. Dereka, B. S. Ooia \\ ${ }^{a}$ School of Chemical Engineering Universiti Sains Malaysia, Engineering Campus 14300 Nibong Tebal, Pulau Pinang, Malaysia \\ ${ }^{b}$ Departement of Chemical Engineering Universitas Negeri Semarang, Kampus Sekaran, Gunungpati, 50229 Semarang, Indonesia \\ *Corresponding author: chlatif@eng.usm.my
}

\section{Article history}

Received :21 August 2013

Received in revised form :

30 October 2013

Accepted :15 November 2013

\section{Graphical abstract}

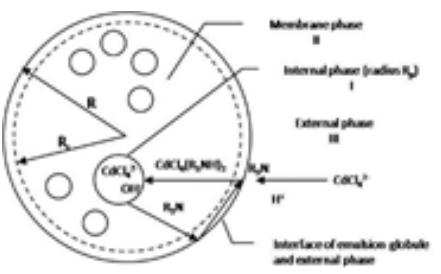

\section{Abstract}

A study on mass transfer model for cadmium extraction in emulsion liquid membrane system has been done. Mass transfer in the external phase and emulsion globule, stripping reaction, and diffusion of the complex were taken account into the model. Reaction and chemical equilibrium of the process were also considered. The partial differential equation was numerically solved using MATLAB software. Effect of some parameters such as acid concentration in the external phase, extraction speed, volume ratio of emulsion to feed phase, volume ratio of internal to membrane phase, and initial concentration to the extraction process were investigated and compared to the model. The model prediction can agree very well with the concentration profile of cadmium in each phase.

Keywords: Model prediction; cadmium; emulsion liquid membrane

(C) 2013 Penerbit UTM Press. All rights reserved.

\subsection{INTRODUCTION}

Cadmium is an extremely poisonous metal that the World Health Organization (WHO) has established a provisional tolerable weekly intake (PTWI) for cadmium at $7 \mu \mathrm{g} / \mathrm{kg}$ of body weight (1). Human intake of cadmium can occur by ingestion and inhalation. Cadmium may alter into the human body through the contaminated food.

In the human body, cadmium is reported to cause kidney malfunction. At high doses, cadmium may ruin the respiratory system. Considering the toxicity of cadmium, its recovery process is of important. So far, cadmium has been removed and recovered by coagulation, activated carbon adsorption, ion exchange, reverse osmosis, chemical precipitation, and liquidliquid extraction. Due to the very low concentration of cadmium in the waste water, cadmium recovery through chemical precipitation, ion exchange, and solvent extraction are not economical $(2,3)$. Moreover, heavy metals cannot be absorbed by activated carbons because of the insufficient functional groups (4). Besides, the process takes relatively long adsorption equilibrium time thus becomes not practical.

Emulsion liquid membrane (ELM) was invented to overcome the limitations of liquid-liquid extraction process. The simultaneous processes of extraction and stripping in a system are offered as the advantage of ELM, in term of energy, time, and equipments saving. Besides, this process requires less solvent, makes it more environmentally friendly. It is reported that compared to that of liquid-liquid extraction, the material costs in the ELM process are $40 \%$ lower (5).

The separation process occurs in thin liquid layer thus it has high transfer rate. The tiny emulsion provides high interfacial area of $3000 \mathrm{~m}^{2} / \mathrm{m}^{3}$ (6). In the ELM process, there are two transport mechanisms. For the solute which is slightly soluble in the membrane phase, the mass transfer was driven by the concentration gradient between the external and internal phase. The solubility of the solute is the controlling parameter that determines the mass transfer rate by diffusion. Once the solute diffused into the internal phase, it will react with the stripping agent and cannot diffuse back to the external phase because of the insolubility of the complex. This is a typical phenomenon for the extraction of phenol using ELM system. On the other hand, for type II facilitated transport, the solute is insoluble in the membrane phase; an extractant is needed to carry the solute from external phase into internal phase. In external phase, solute will react with the extractant which is soluble in membrane phase. After the extractant-solute complex reached internal phase, the solute will be released and react with the stripping agent. The extractant will then diffuse back to external phase to form new extractant-solute complex. This transport mechanism occurs in the extraction of heavy metals.

There were number of studies have been attempted in the cadmium recovery using ELM system (7-10). However mathematical modeling of the cadmium mass transfer using ELM was found lacking in the literatures. In this paper, a carrier facilitated transport model is proposed to study the cadmium 
recovery by ELM process using Trioctylamine (TOA) as a carrier under various experimental conditions. In our study, TOA facilitated the transport mechanism of cadmium into the internal phase. TOA reacted with cadmium ion in the interface of external phase, formed extractant-solute complex. The concentration gradient encouraged the complex to diffuse into the internal phase. Inside, the cadmium ion was released while TOA diffused back to external phase. The cadmium ion was stripped by ammonia $\left(\mathrm{NH}_{3}\right)$ in the internal phase.

The dimensional model of emulsion globule can be differentiated into five schemes model, namely: i) uniform flatplate model, ii) hollow sphere model, iii) immobilized hollow sphere model, iv) immobilized spherical globule model, and v) immobilized hollow spherical globule model. The first emulsion globule model assumes that droplets are coalesced to become a single large droplet. In this model, the membrane thickness is assumed to be constant and solute will diffuse through this stagnant membrane into the internal phase (11).The second emulsion globule model was then developed to be more complex, in which all the droplets were well mixed in the globule and assumed to be single drop surrounded by hollow spherical shell of membrane phase(11). In case of the membrane thickness is too small compared to the globule, they omitted the radius curvature. This simple model is reported to be inaccurate except the thickness parameter can be manipulated (11). This second model is similar to the first flat sheet model, except the membrane film is in hollow spherical form. While the third immobilized hollow sphere model assumes that the internal droplets are immobile. The reaction of solute and stripping agent is irreversible. In immobilized spherical globule model, the internal droplets are heterogeneously distributed within the globule. The last model has the similar characteristic, except for the peripheral membrane layer that surrounds the droplets. In this model, mass transfer occurs in three stages of diffusion, i.e. through external boundary layer, peripheral membrane layer, and internal droplet (11)

Mathematical models dealing with type II facilitated transport for metal extraction have been developed by some researchers. Diffusion through emulsion globule and reversible reaction at the interfaces of external and internal phases were taken into account. The first model was done by Teramoto et al. (12) which considered mass transfer on external phase and phenomenon of membrane breakage. Lorbach and Marr (13) considered the extraction and stripping reaction of $\mathrm{Zn}^{2+}$ and extractant. More complex model was developed by Kataoka et al. (14) by considering the mass transfer resistance of the peripheral thin membrane layer. Yan (15) developed a model for type II facilitated transport of gold by emulsion liquid membrane. It incorporated the mass transfer and the first order reaction inside and outside the emulsion globule. The model could predict and analyze the behavior of extraction process; approximate solution was obtained by perturbation method. Weiss et al.(16) studied the extraction of mercury using dibutylbenzoylthiourea as carrier. The mass transfer in the interface of external and membrane phase, the complex diffusion through membrane phase, and the reversible reaction at the interface of external and internal phase were taken into account. Banerjea and Chakraborty also developed unsteady state mathematical models to describe type II facilitated transport $(17,18)$.

In this work a model for type II facilitated transportof cadmium based on the immobilized hollow spherical globule model by taking into account mass transfer resistance in the external phase and emulsion globule, stripping reaction, and diffusion of the complex was proposed. Schematic of the model is presented in Figure 1.

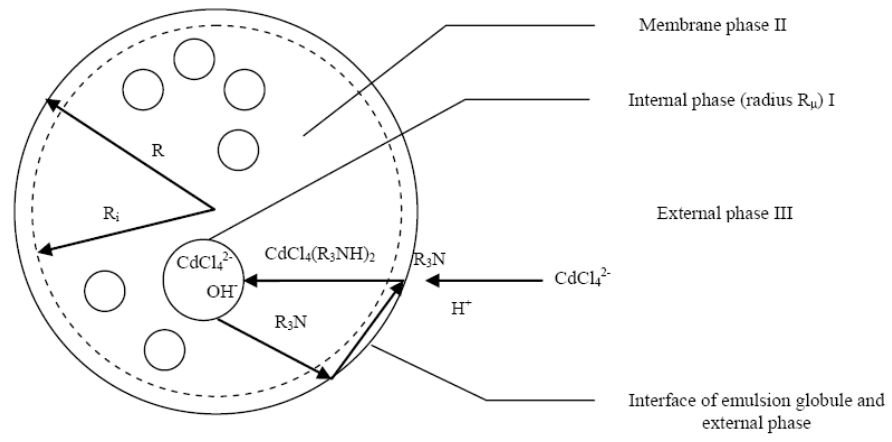

Figure 1 Extraction model of extraction process in ELM system

\subsection{EXPERIMENTAL}

\subsection{Materials}

Deionized water was used for all of the solutions preparation. The membrane phase consisted of kerosene (commercial grade), non-ionic surfactant (Span 80, Merck), and carrier (Trioctylamine, Merck). Cadmium solution was prepared from cadmium chloride, supplied by Sigma Aldrich. Stripping solution was prepared from a $25 \%$ solution of ammonia, supplied by Merck. pH was adjusted using $\mathrm{HCl}$ and $\mathrm{NaOH}$, supplied by Merck.

An ultrasonicator was used to prepare the emulsion. The emulsification setup consisted of a jacketed cylindrical glass reactor, allowing the emulsification cell to be cooled with water. Ultrasonic irradiation was performed at $22.5 \mathrm{kHz}$ using a USG150 commercial ultrasonicator equipped with a titanium horn mounted at the top of the cylindrical glass cell. A predetermined volume of Span 80 and TOA were dissolved in kerosene and stirred at $500 \mathrm{rpm}$ for $5 \mathrm{~min}$ using magnetic stirrer to prepare the membrane phase. An adequate amount of $0.1 \mathrm{M}$ ammonia as the internal aqueous phase was then added into the prepared membrane phase solution. The mixture was then homogenized using the ultrasonicator by immersing the probe at the interface of the membrane-internal phase. Coolant was circulated around the jacket to maintain the process temperature at $20^{\circ} \mathrm{C}$.

Extraction studies were carried out by dispersing the emulsion into the feed phase, of cadmium chloride in deionized water. The experiments were performed in a glass stirred vessel. In this step, the extraction speed, initial concentration of the feed phase, treatment ratio (volume ratio of feed to emulsion phase), and acid concentration in the feed phase were varied (see Table 1) to determine the optimal extraction efficiency of $\mathrm{Cd}(\mathrm{II})$. Each experiment was performed in triplicate, and the mean values are presented.

\subsection{Characterizations}

Emulsion size was measured using Malvern Mastersizer. Cadmium concentration in the external feed phase was measured using an atomic absorption spectrophotometer (AA6650 Shimadzu) at wavelength of $228.85 \mathrm{~nm}$. $\mathrm{pH}$ of the solution was measured using a Fisher Scientific Accumet AB15 pH meter.

At the end of extraction, the emulsion phase was separated from the feed phase using a separatory funnel, and the aliquots were collected to analyze the $\mathrm{Cd}(\mathrm{II})$ concentration using Atomic Absorption Spectrophotometre (AAS). 


\subsection{RESULTS AND DISCUSSION}

\subsection{Reaction and Chemical Equilibrium}

For cadmium extraction, a carrier is required in the organic membrane phase to facilitate the diffusion of cadmium in the emulsion. The cadmium from the external phase reacts with extractant (trioctylamine) to form cadmium-extractant complexes at surface of the emulsion globules then diffuses through the organic membrane phase. At the membrane-internal phase interface, a stripping reaction occurs with the internal reagent present in the internal droplets via a reversible reaction. These reactions can be written as follows:

Extraction reaction:

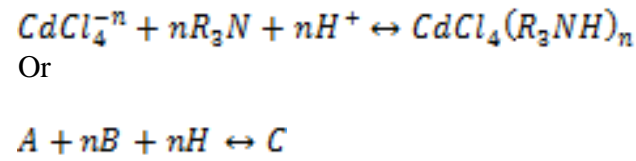

Stripping reaction:

$$
\mathrm{CdCl}_{4}\left(\mathrm{R}_{\mathrm{a}} \mathrm{NH}\right)_{\mathrm{n}}+n \mathrm{OH}^{-} \leftrightarrow \mathrm{CdCl}_{4}^{-n}+n R_{\mathrm{a}} \mathrm{N}+n \mathrm{H}_{2} \mathrm{O}
$$

Or

$C+n O H \leftrightarrow A+n B$

where $R_{a} N$ denotes the extractant and $\mathrm{CdCl}_{4}\left(R_{a} N H\right)_{n}$ is the solute-extractant complex.

The equilibrium constant for reaction (1) can be expressed as:

$K_{e q}=\frac{\left[c_{c}\right]}{\left[c_{d}\right]\left[c_{g}\right]^{n}\left[c_{H}\right]^{n}}=\frac{\left[c_{c}\right]}{\left[c_{g}\right]^{n}\left[c_{d}\right]^{n+1}}$

Due to the stoichiometry for extraction reaction, the following expression holds:

$C_{B}^{0}=C_{B}+C_{C}$

where $C_{B}^{0}$ denotes the initial concentration of extractant in the organic membrane phase. Combining Equations (3) and (4) yields:

$$
\left[C_{C}\right]_{r=R}=K_{e q}\left[C_{A}\right]^{n+1}\left(\left[C_{B}^{0}\right]-\left[C_{C}\right]_{r=R}\right)^{n}
$$

which specifies the solute-extractant complex concentration and can be solved by optimization.

\subsection{Distribution Coefficient}

Distribution coefficient $\left(K_{D}\right)$ is defined as the ratio of extracted metal concentration in organic phase and un-extracted metal concentration in the external phase. So, from Equation (3), we get:

$$
K_{e q}=\frac{K_{D}}{\left[c_{B}\right]^{n}\left[c_{H^{1}}\right]^{n}}
$$

Or

$$
K_{D}=K_{e q}\left[R_{a} N\right]^{n}\left[H^{+}\right]^{n}
$$

Taking logarithms of Equation (7), the following equation will obtain:

$$
\log \left(K_{D}\right)=\log \left(K_{\varepsilon q}\right)+n \log \left(\left[R_{\mathrm{a}} N\right]\right)+n \log \left(\left[H^{+}\right]\right)
$$

Or

$$
\log \left(K_{D}\right)=\log \left(K_{e q}\right)+n \log \left(\left[R_{a} N\right]-p H\right)
$$

The plots of $\log \left(K_{D}\right)$ versus $\log \left(\left[R_{3} N\right]-p H\right)$ will give a straight line of slope $n$ and the intercept is equal to $\log \left(K_{e q}\right)$.

\subsection{Mass Transfer Model}

As shown in the figure, $R_{i}, R$, and $R_{\mu}$ are the inner radius of emulsion globule, radius of emulsion globule, and radius of internal droplet, respectively whereas I, II, and III refer to the internal phase, membrane phase, and external phase, respectively. Some assumptions were made to simplify the model as follow:

1. The extraction system is well mixed that the concentration of $\mathrm{Cd}^{2+}$ is uniform.

2. The emulsion globule is monodisperse and spherical, the diameter of emulsion globule as well as internal droplets could be defined by Sauter mean diameter.

3. The internal droplets are immobile and heterogeneously distributed.

4. Membrane leakage and swelling are negligible.

5. The mass transfer in the membrane phase is occurred by diffusion, the effective diffusivity in the membrane phase is constant.

6. The volume of each phase is constant.

7. Due to the tiny internal droplets, the interfacial mass transfer resistance between membrane and internal phase is negligible.

a. Mass balance of cadmium in external phase:

$-k_{C} S\left(\left.C_{C}\right|_{r=R}-\left.C_{C}\right|_{r=R i}\right)=V_{U I} \frac{d C_{A M}}{d t}$

where $\mathrm{k}_{\mathrm{c}}$ is the external mass transfer coefficient $(\mathrm{cm} / \mathrm{s}) ; \mathrm{S}$ istotal interfacial area of emulsion globule $\left(\mathrm{cm}^{2}\right) ; \mathrm{C}_{\mathrm{A}, \mathrm{III}}$ is concentration of cadmium in the external phase $(\mathrm{mg} / \mathrm{L}) ; \mathrm{C}^{0}{ }_{\mathrm{A}, \mathrm{III}}$ is initial concentration of cadmium in the external phase $(\mathrm{mg} / \mathrm{L})$; $\mathrm{C}_{\mathrm{C}}$ is concentration of the cadmium-carrier complex at the external phase-membrane interface $(\mathrm{mg} / \mathrm{L})$; and $\mathrm{V}_{\text {III }}$ is volume of external phase $\left(\mathrm{cm}^{3}\right)$.

b. Mass balance of cadmium-carrier complex (C) within emulsion globules $0 \leq \mathrm{r} \leq \mathrm{R}_{\mathrm{i}}$

$\left(V_{I}+V_{U I}\right)_{i} D_{\Theta_{u} C}\left[\frac{1}{r^{2}} \frac{\partial}{\partial r}\left(r^{2} \frac{\partial C_{c}}{\partial r}\right)\right]-S_{m i} R_{x}=V_{I I} \frac{\partial C_{C}}{\partial t}$

Interfacial area between membrane and internal droplet,

$\mathrm{S}_{\mathrm{mi}}\left(\mathrm{cm}^{2}\right)$ and volume of internal phase, $V_{I}\left(\mathrm{~cm}^{3}\right)$ are given as follow:

$S_{\mathrm{mi}}=4 \pi R_{\mu}^{2}$

$V_{I}=\frac{4}{a} \pi R_{\mu}^{3}$

Thus, the interfacial area between membrane and internal droplet can then be expressed as:

$S_{\mathrm{mi}}=\frac{a}{R_{\mu}} V_{I}$

Equation (11) becomes: 
$\left(V_{I}+V_{U I}\right)_{i} D_{\theta_{u} C}\left[\frac{1}{r^{2}} \frac{\partial}{\partial r}\left(r^{2} \frac{\partial C_{c}}{\partial r}\right)\right]-\frac{a V_{I}}{R_{\mu}} R_{x}=V_{U I} \frac{\partial C_{C}}{\partial t}$

Or

$\left(V_{I}+V_{I I}\right)_{i} D_{e_{u} C}\left[\frac{\partial^{2} C_{C}}{\partial r^{2}}+\left(\frac{2}{r} \frac{\partial C_{C}}{\partial r}\right)\right]-\frac{\partial V_{I}}{R_{\mu}} R_{x}=V_{I I} \frac{\partial C_{C}}{\partial t}$

where $V_{I I}$ is the volume of membrane phase $\left(\mathrm{cm}^{3}\right), D_{e, C}$ is the effective diffusivity of cadmium-carrier complex in emulsion phase $\left(\mathrm{cm}^{2} / \mathrm{s}\right)$, and $R_{x}$ is rate of stripping $(\mathrm{mg} / \mathrm{L} / \mathrm{s})$.

c. Mass balance of carrier (B) within emulsion globule $0 \leq \mathrm{r} \leq$ $\mathrm{R}_{\mathrm{i}}$

Analog to Equation (16), mass balance of carrier (B) within emulsion globule is given by:

$\left(V_{U}+V_{U I}\right)_{i}\left\{D_{\Theta_{i} B}\left[\frac{\partial^{2} C_{B}}{\partial r^{2}}+\left(\frac{2}{\partial} \frac{\partial C_{B}}{\partial r}\right)\right]+D_{\theta_{i} C}\left[\frac{\partial^{2} C_{C}}{\partial r^{2}}+\left(\frac{2}{r} \frac{\partial C_{C}}{\partial r}\right)\right]\right\}=V_{U I}($

where $C_{B}$ is the concentration of cadmium-carrier complex at the external-membrane interface $(\mathrm{mg} / \mathrm{L})$ and $D_{e, B}$ is the effective diffusivity of carrier in emulsion phase $\left(\mathrm{cm}^{2} / \mathrm{s}\right)$.

Volume ratio of emulsion globule:

$\frac{\left(V_{R}+V_{H}\right)_{i}}{\left(V_{R}+V_{h}\right)}=\left(\frac{R_{i}}{R}\right)^{a}$

or

$\left(V_{I}+V_{U I}\right)_{i}=\left(V_{I}+V_{U}\right)(1-\theta)^{a}$

where $\theta$ is the thickness of the thin oil layer, $\theta=1-\left(\frac{R_{i}}{R}\right)$. By dividing Equations (16) and (17) with $\left(V_{I}+V_{I I}\right)$, the equations become:

$\frac{V_{M}}{\left(V_{I}+V_{M}\right)(1-\theta)^{3}} \frac{\partial C_{C}}{\partial t}=D_{\theta_{\alpha} C}\left[\frac{\partial^{2} C_{C}}{\partial r^{2}}+\left(\frac{2}{r} \frac{\partial C_{C}}{\partial r}\right)\right]-\frac{1}{\left(V_{T}+V_{T I}\right)(1-\theta)^{3}} \frac{a V_{I}}{R_{\mu}} R_{X}$

$\frac{V_{I I}}{\left(V_{I}+V_{I I}\right)(1-\theta)^{3}}\left(\frac{\partial C_{B}}{\partial t}+\frac{\partial C_{C}}{\partial t}\right)=D_{e, B}\left[\frac{\partial^{2} C_{B}}{\partial r^{2}}+\left(\frac{2}{r} \frac{\partial C_{B}}{\partial r}\right)\right]+D_{\theta_{u} C}\left[\frac{\partial^{2} C_{C}}{\partial r^{2}}+\left(\frac{2}{r} \frac{\partial C_{C}}{\partial r}\right)\right]$

Equations (20) and (21) can then be written as:

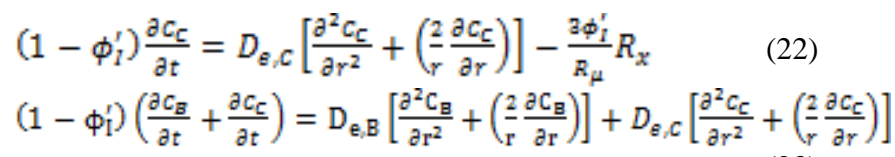

where:

$\phi_{I}^{\theta}=\frac{\phi_{I}}{(1-\theta)^{3}}$

$\phi_{I}=\frac{V_{I}}{\left(V_{I}+V_{H}\right)}$

d. Mass balance of cadmium (A) in the internal phase

$V_{I} \frac{a C_{A, I}}{d t}=\frac{a V_{I}}{R_{\mu}} R_{x}$

or

$\phi_{I}^{s} \frac{d C_{A_{I} I}}{d t}=\frac{a \phi_{I}^{*}}{R_{\mu}} R_{x}$

Initial and boundary conditions (ICs, BCs) subjected to the equations above are given as follows:

ICs:

For $\mathrm{t}=0 ; \quad \mathrm{C}_{\mathrm{A}, \mathrm{III}}=\mathrm{C}^{0}{ }_{\mathrm{A}, \mathrm{III}}$

For $\mathrm{t}=0,0 \leq \mathrm{r} \leq \mathrm{R} ; \quad \mathrm{C}_{\mathrm{B}}=\mathrm{C}^{0}{ }_{\mathrm{B}} ; \mathrm{C}_{\mathrm{C}}=0 ; \mathrm{C}_{\mathrm{A}, \mathrm{I}}=0$
BCs:

$$
\begin{aligned}
& \text { For } \mathrm{t} \geq 0, \mathrm{r}=0 ; \quad \frac{\partial C_{B}}{\partial y}=0 ; \frac{\partial C_{C}}{\partial y}=0 \\
& \text { For } \mathrm{t} \geq 0, \mathrm{r}=\mathrm{R}_{\mathrm{i}} ; \quad-D_{\Theta_{B} B}\left(\frac{\partial C_{B}}{\partial y}\right)=D_{Q_{y} C}\left(\frac{\partial C_{C}}{\partial y}\right) \\
& =k_{B}\left(\left.C_{B}\right|_{r=R i}-\left.C_{B}\right|_{r=R}\right)=k_{C}\left(\left.C_{C}\right|_{Y=R}-\left.C_{C}\right|_{Y=R i}\right)
\end{aligned}
$$

where $\mathrm{k}_{\mathrm{B}}$ and $\mathrm{k}_{\mathrm{C}}$ are the mass transfer coefficients of carrier (B) and solute $(\mathrm{C})$ in the peripheral thin oil layer respectively. $\phi_{I}$ is the volume fraction of the internal phase in emulsion drop.

\subsection{Numerical Solution}

- Numerical method of lines approach was applied to solve the above partial differential equations, transforming each partial differential equation into ordinary differential equations based on discretisation of the spatial derivative. The radius of emulsion globule is separated into $n$ intervals or $(n+1)$ points as shown in Figure 2.

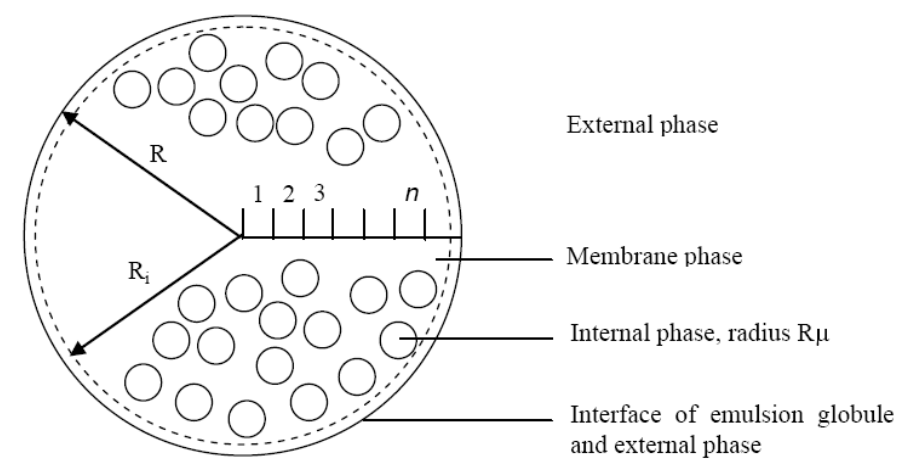

Figure 2 Separation of emulsion globule radius into $n$ interval for numerical analysis

Based on this illustration, Equations (22) and (23) were derived numerically using centered finite difference method to obtain the following expressions.

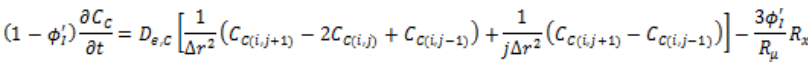

$$
\begin{aligned}
& \left(1-\phi_{I}^{\prime}\right)\left(\frac{\partial C_{B}}{\partial t}+\frac{\partial C_{c}}{\partial t}\right)
\end{aligned}
$$

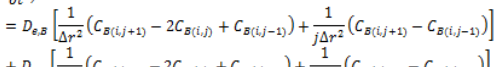

$$
\begin{aligned}
& +D_{\varepsilon, c}\left[\frac{1}{\Delta r^{2}}\left(c_{C(i, j+1)}-2 C_{C(i, i)}+C_{C(i, j-1)}\right)+\frac{1}{j \Delta r^{2}}\left(c_{C(i, j+1)}-C_{C(i, j-1)}\right)\right]
\end{aligned}
$$

where

$$
\begin{aligned}
& \mathrm{i}=1,2,3, \ldots \ldots n \\
& \mathrm{j}=1,2,3, \ldots \ldots n
\end{aligned}
$$

Equations (32) and (33) are only valid when $r \neq 0$. For $r=0$, Equation (22) and (23) become:

$$
\begin{aligned}
& \left(1-\phi_{I}^{v}\right) \frac{\partial C_{C}}{\partial t}=D_{\theta_{\alpha} C}\left(3 \frac{\partial^{2} C_{C}}{\partial r^{2}}\right)-\frac{\partial \phi_{I}^{s}}{R_{\mu}} R_{x} \\
& \left(1-\phi_{I}^{t}\right)\left(\frac{\partial C_{B}}{\partial t}+\frac{\partial C_{C}}{\partial t}\right)=D_{\epsilon_{i} B}\left(3 \frac{\partial^{2} C_{B}}{\partial r^{2}}\right)+D_{\theta_{i} C}\left(3 \frac{\partial^{2} C_{c}}{\partial r^{2}}\right)
\end{aligned}
$$

On the other hand, the equations at the boundaries would have to be modified according to the boundary conditions in Equation (31). 


$$
\begin{aligned}
& C_{C[n+1)}=\frac{2 k_{C} \Delta r}{D_{Q, C} C}\left(\left.C_{C}\right|_{y=R}-\left.C_{C}\right|_{y=R i}\right)+C_{C[n-1)} \\
& C_{E[(n+1)}=\frac{2 k_{B} \Delta r}{D_{Q, B}}\left(\left.C_{B}\right|_{y=R}-\left.C_{B}\right|_{y=R i}\right)+C_{E[(n-1)}
\end{aligned}
$$

where $r=R_{i}=n=$ the point at the radius of inner core of W/O emulsion drop. $\left.C_{C}\right|_{r=R}$ and $\left.C_{B}\right|_{r=R}$ can be calculated by the equilibrium relation at theexternal interfacebetween the external and the membranephase. These systems of equations of Equation (10), (27), and (32-37) using the conditions of Equations (28-31) were solved simultaneously by Runge-Kutta forth degree using MATLAB software.

\subsection{Effective Diffusivity}

The diffusivity of cadmium in the internal phase $\left(D_{i}\right)$ and in the membrane phase $\left(D_{m}\right)$ are determined by using Wilke-Chang equation (19).

$D=7.4 \times 10^{-8} \frac{T M^{1 / 2}}{\eta V^{0.6}}$

where $T$ is the temperature $(\mathrm{K}), M$ is the molecular weight of solvent, $\eta$ is the viscosity of solution $(\mathrm{cP})$, and $V$ is the molal volume of solute.

Based on Equation (38), $D_{i}$ and $D_{m}$ were calculated to be $1.42723 \times 10^{-05} \mathrm{~cm}^{2} / \mathrm{s}$ and $4.31535 \times 10^{-06} \mathrm{~cm}^{2} / \mathrm{s}$, respectively. While the effective diffusivity of complex in the membrane phase $\left(D_{e, C}\right)$ is governed using Jefferson-Witzell-Sibbelt equation(20).

$D_{\theta_{\alpha} C}=D_{m}\left\{1-\frac{\pi}{4(1+2 p)^{2}}\right\}+\frac{\pi}{4(1+2 p)}\left(\frac{D_{m} D_{A}}{D_{m}+2 p D_{A}}\right)$

Where

$D_{A}=\frac{\left.2 L D_{i} / \alpha_{i}\right] D_{m n}}{D_{i} / \alpha_{i}-D_{m}}\left\{\frac{D_{i} / \alpha_{i}}{D_{i} / \alpha_{i}-D_{m n}} \ln \left(\frac{D_{i}}{\alpha_{i} D_{m n}}\right)-1\right\}$

and

$p=0.403 \phi_{I}^{-1 / a}-0.5$

\subsection{Mass Transfer Coefficient}

The external mass transfer coefficient $k_{C}$ is determined using Skelland and Lee equation(20). It depends on the given operating condition.

$$
k_{C}=\left(N D_{i}\right)^{1 / 2} \times 2.932 \times 10^{-7} \phi_{e}^{-0.509}\left(\frac{D_{D}}{T}\right)^{0.548} R e^{1.971}
$$

where $N$ is the extraction speed (rps), $D_{p}$ is the propeller diameter $(\mathrm{cm}), \phi_{e}$ is the volume ratio of emulsion to feed phase, $T$ is the tank diameter $(\mathrm{cm})$, and $R e$ is Reynolds number.

The mass transfer coefficient of the oil phase membrane $\left(k_{m}\right)$ was determined using equation of Lee and Chan (20) which depends on the used emulsion composition.

$k_{m}=\frac{D_{m}}{\left(R / R_{i}\right)\left(R-R_{i}\right)}$

The interfacial mass transfer coefficient $(k)$ was estimated using Loosemore and Prosser equation (21) to be $0.04230 \mathrm{~cm} / \mathrm{s}$.

$k=v \times 61 S c^{-0.92}$ where $v$ is the kinematic viscosity of surfactant $\left(\mathrm{cm}^{2} / \mathrm{s}\right)$ and $S c$ is Schmidt number.

Finally, the overall mass transfer resistance is calculated as follow:

$\frac{1}{k}=\frac{1}{k_{c}}+\frac{1}{k}+\frac{1}{m \cdot k_{m}}$

\subsection{Emulsion Diameter}

The droplet and globule diameter can be expressed as Sauter diameter $\left(\mathrm{d}_{32}\right)$ which represents the average surface diameter as developed by Josef Sauter in the 1926.

$d_{a 2}=\frac{\sum_{i} n_{i} d_{i}^{3}}{\sum_{i} n_{i} d_{i}^{2}}=6 \frac{V}{A}$

where $n_{i}, d_{i}$ are the droplets number and diameter for the $i^{\text {th }}$ class, while $\mathrm{V}$ and $\mathrm{A}$ refer to the dispersed phase volume and area, respectively. The diameters vary depend on the emulsion composition and preparation condition.

For determining the size of emulsion droplet, the W/O emulsion was measured using microscope and then analyzed using image analyzer. The sauter mean diameter of emulsion droplets found is $0.877 \mu \mathrm{m}$.

The size distribution of emulsion globules depends on the extraction speed and the emulsion properties. Reis and Carvalho (22) formulated the size of emulsion globules as a function of extraction speed as follows:

$\log \left(d_{12}\right)=-(1.4 \pm 0.2) \log (N)-2.4$

where the sauter mean diameter of emulsion globules, $d_{32}$ in meter and the extraction speed, $N$ in rps. For extraction speed ranging from $200 \mathrm{rpm}$ to $500 \mathrm{rpm}$, the sauter mean diameter of emulsion globules calculated from aforementioned equation are in the range of $0.7-0.2 \mathrm{~mm}$.

\subsection{Effect of Acid Concentration}

The study on the effect of acid concentration in the feed phase to the extraction process was done using $\mathrm{HCl}$ concentration of $0.05 \mathrm{M}, 0.1 \mathrm{M}$, and $0.5 \mathrm{M}$. It can be seen from Fig. 3 that the degree of extraction increased as the acid concentration increased. Rapid extraction was obtained at the highest $\mathrm{HCl}$ concentration of $0.5 \mathrm{M}$ related in the lowest solution $\mathrm{pH}$. Especially when the solute concentration in the external and internal phase is almost the same, the $\mathrm{pH}$ gradient in the external and internal phases acts as driving force for the diffusion process. Without any concentration gradient, the extraction rate will decrease sharply. In this situation, the $\mathrm{pH}$ gradient plays an important role to ensure the continuity of diffusion process. Moreover, the increase of acid concentration until certain value can ionize the cadmium that simplifies the formation of soluteextractant complex. Therefore, more cadmium can be transported into the internal phase. It is shown by the increase of equilibrium constant as the acid concentration increase; prove that the complex formation (Equation 1) is favourable at higher acid concentration. 


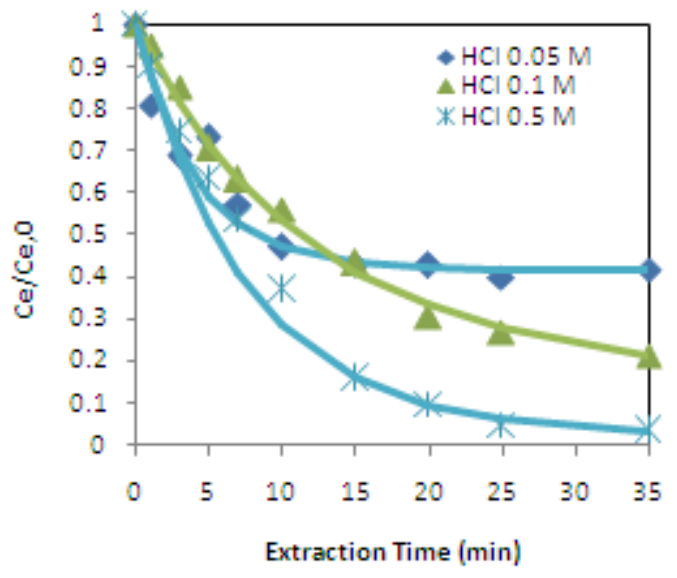

Figure 3 Effect of extraction time to extraction rate at various $\mathrm{HCl}$ concentration

\subsection{Effect of Stirring Speed}

Effect of stirring speed to cadmium extraction is given in Fig. 4. Solid line shows the predicted data. The effect of stirring speed to extraction process was studied within the range of 200 to 600 $\mathrm{rpm}$. The figure shows that extraction rate increased as the increase of stirring speed. It can be explained that accelerating the stirring speed resulted in the decrease of external mass transfer resistance. This experiment showed that stirring the solution at 200 and $300 \mathrm{rpm}$ resulted in insignificant difference on rate of extraction. Higher extraction rate can be achieved at stirring speed of $600 \mathrm{rpm}$. At $600 \mathrm{rpm}$, ELM system reached equilibrium within the first $5 \mathrm{~min}$ of extraction, faster than others which reached equilibrium only after around $20 \mathrm{~min}$. The increase of extraction speed enhanced the external mass transfer coefficient $(\mathrm{kc})$ thus more cadmium was extracted into emulsion. The $\mathrm{k}_{\mathrm{C}}$ value was in the following order: $200 \mathrm{rpm}<$ $300 \mathrm{rpm}<600 \mathrm{rpm}$.

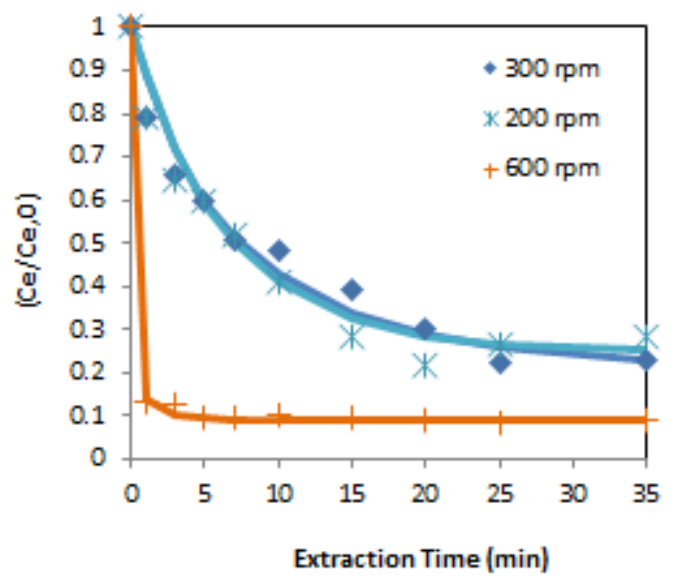

Figure 4 Effect of extraction time to extraction rate at various stirring speed

\subsection{Effect of Volume Ratio of Emulsion to Feed Phase}

Effect of volume ratio of emulsion to feed phase is shown in Fig. 5. The effect of volume ratio of emulsion to feed phase to degree of extraction was enhanced by the increase of volume ratio of emulsion to feed phase. It is due to the increase of total emulsion globule and interfacial area between the feed and emulsion phase as explained in the following equations:

$S=\frac{a \times V_{(x+N)}}{R}$

Substituting Equation (48), Equation (10) becomes:

$$
\begin{aligned}
& V_{I N I} \frac{d C_{g}}{d t}=-k_{C} \frac{a \times V_{\left(T+M T^{2}\right)}}{R}\left(\left.C_{C}\right|_{\gamma=R}-\left.C_{C}\right|_{\gamma=R i}\right) \\
& \frac{d C_{g}}{d t}=-k_{C} \frac{a \times V_{(T+H T)}}{R \times V_{H I}}\left(\left.C_{C}\right|_{Y=R}-\left.C_{C}\right|_{Y=R i}\right)
\end{aligned}
$$

More stripping agent also provided simultaneously therefore the stripping capacity will also increase. However, the use of emulsion must also be considered very well to maintain the process to be economically feasible.

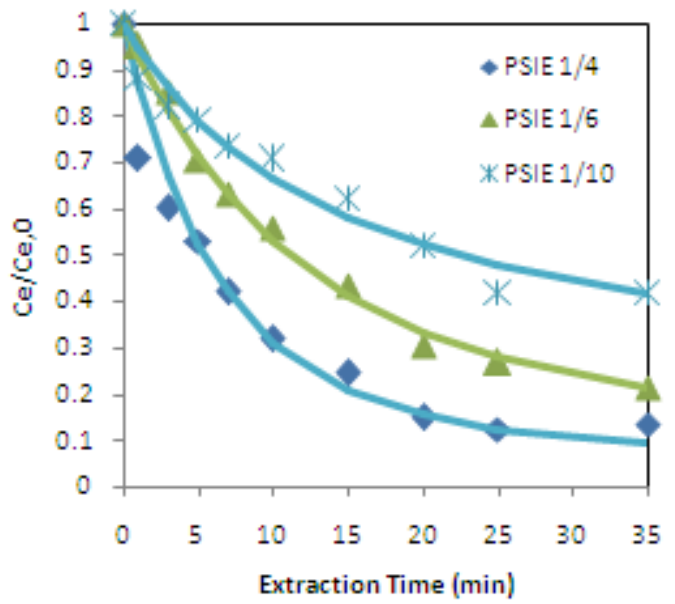

Figure 5 Effect of extraction time to extraction rate at various volume ratio of emulsion to feed phase

\subsection{Effect of Initial Concentration}

The gradient concentration of cadmium in external and internal phase is the driving force for mass transfer process. In this experiment, the initial concentration was varied at 100, 150, and $200 \mathrm{ppm}$. Experimental and calculation data are presented in Fig. 6. The experiment results showed initial Cd concentration gave no significant different on degree of extraction. The profile of concentration ratios was quite similar because the $\mathrm{kL}_{\mathrm{L}}$ value is constant for all $\mathrm{Cd}$ concentration, although theoretically the higher initial concentration will give higher driving force. The result agreed very well with the model. 


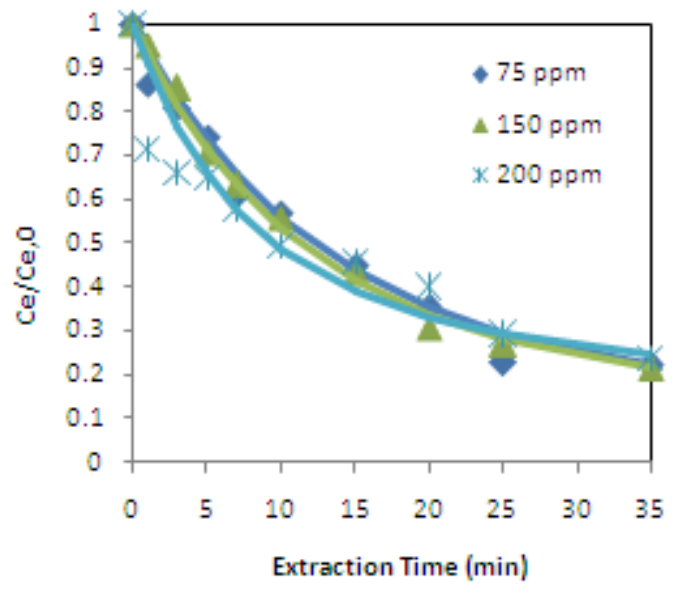

Figure 6 Effect of extraction time to extraction rate at various initial $\mathrm{Cd}$ concentration

\subsection{Effect of Volume Ratio of Internal to Membrane Phase}

Study was carried out for the volume ratio of internal to membrane phase at ratio of $1 / 2,1 / 3$, and $1 / 5$. Variation of this phase ratio produced emulsions with different properties, including size, stability, and extraction capacity. Optimal phase ratio produces proper size of emulsion. Less membrane phase is not enough to enclose the overall internal phase thus producing large emulsion globule. The produced emulsion tends to have thin wall therefore increasing leakage possibility. On the contrary, too much membrane phase produces thick emulsion wall which is not favorable for the extraction process due to the enlargement of diffusion path which in turn will decrease the mass transfer rate. Fig. 7 shows that optimal result was reached at phase ratio of $1 / 3$. Our previous study showed that phase ratio of $1 / 3$ produced the smallest emulsion droplets as well as the most stable emulsion (23). Fine emulsion globule is favorable due to the high interfacial area for the same volume, as explained in equation (17). Bigger emulsion has lower $\mathrm{km}$ therefore decreasing the extraction rate.

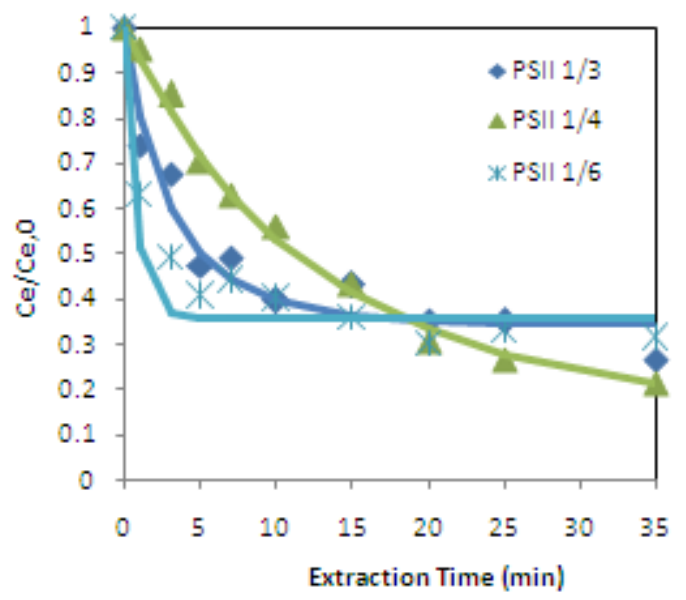

Figure 7 Effect of extraction time to extraction rate at various volume ratio of internal to membrane phase

\subsection{CONCLUSION}

The experimental data show the effectiveness of cadmium extraction using emulsion liquid membrane. TOA was used to facilitate cadmium transport into the internal phase. The modeling was done by taking into account mass transfer in the external phase and emulsion globule, diffusion of the complex, and stripping reaction. The effects of various experimental conditions such as volume ratio of internal to membrane phase, extraction speed, initial concentration, acid concentration in the external phase, and volume ratio of emulsion to feed phase were simulated by the model. The mass transfer coefficient directly affected the extraction rate for the parameter of extraction speed and volume ratio of internal membrane phase; while equilibrium constant governed the extraction rate for the variation of acid concentration. The parameter of volume ratio of emulsion to feed phase influenced the extraction rate from its interfacial area and equilibrium constant. No significant effect of initial concentration of cadmium to the extraction rate. The experimental data can be well explained by the model. For the standard condition, the standard mean deviation was found to be $3 \%$.

\section{Acknowledgement}

The PRGS and Membrane Science and Technology Research University Cluster from Universiti Sains Malaysia are gratefully acknowledged.

\section{References}

[1] L. Friberg, C.G. Elinder, T. Kjellstrom. 1992. Cadmium. Available from: http://www.inchem.org/documents/ehc/ehc/ehc134.htm.

[2] Y. Xu, L. Yang, J. Yang. 2010. International Journal of Engineering, Science and Technology. 2(7).

[3] M. D. C. V. Soares, M. D. A. Bertrand, F. D. A. Lemos, et al. 2005 Removal of Lead, Cadmium and Zinc from Industrial Effluents Using Nanofiltration and Reverse Osmosis Membranes. In XIII International Conference on Heavy Metals in the Environment. R.d.B.E. Trindande, et al. Editors: Rio de Janeiro, Brazil. 1-4.

[4] C. K. Ahn, Y. M. Kim, S. H. Woo, et al. 2009. Hydrometallurgy. 99(34).

[5] A. L. Ahmad, A. Kusumastuti, C. J. C. Derek, et al. 2011. Chemical Engineering Journal. 171(3).

[6] M. Chakraborty, C. Bhattacharya, S. Datta. 2010. Chapter 4 - Emulsion Liquid Membranes: Definitions and Classification, Theories, Module Design, Applications, New Directions and Perspectives. In Liquid Membranes. S.K. Vladimir, Editor. 2010, Elsevier: Amsterdam. 141199.

[7] C. Basualto, M. Poblete, J. Marchese, et al. 2006. Journal of the Brazilian Chemical Society. 17.

[8] R. A. Kumbasar. 2008. Separation and Purification Technology. 63(3).

[9] R. A. Kumbasar. 2009. Hydrometallurgy. 95(3-4).

[10] H. R. Mortaheb, H. Kosuge, B. Mokhtarani, et al. 2009. Journal of Hazardous Materials. 165(1-3).

[11] C. C. Chan, C. J. Lee. 1984. Journal of Membrane Science. 20(1).

[12] M. Teramoto, T. Sakai, K. Yanagawa, et al. 1983. Separation Science and Technology. 18(8).

[13] D. Lorbach, R. Marr. 1987. Chemical Engineering and Processing: Process Intensification. 21(2)

[14] T. Kataoka, T. Nishiki, S. Kimura, et al. 1989. Journal of Membrane Science. 46(1).

[15] N. Yan. 1993. Chemical Engineering Science. 48(22).

[16] S. Weiss, V. Grigoriev, P. Muhl. 1982. Journal of Membrane Science. 12(1).

[17] S. Banerjea, S. Datta, S. K. Sanyal. 2000. Separation Science and Technology. 35.

[18] M. Chakraborty, C. Bhattacharya, S. Datta. 2003. Separation Science and Technology. 38(9).

[19] C. R. Wilke, P. Chang. 1955. A.1.Ch.E. Journal. 
[20] C. J. Lee, C. C. Chan. 1990. Industrial \& Engineering Chemistry Research. 29(1).

[21] D. R. Olander. 1963. Chemical Engineering Science. 18.
[22] M. T. A. Reis, J. M. R. Carvalho. 2004. Journal of Membrane Science. 237(1-2).

[23] A. L. Ahmad, A. Kusumastuti, C. J. C. Derek, et al. 2012. Desalination. 287(0). 